\title{
The Exploration of Creative Paths of Cultivating Medical Humanistic Quality under Media Convergence
}

\author{
Lei Yu \\ School of Medicine Research, Shanghai Jiao Tong University, Shanghai, China \\ Email: leiyu5656@163.com
}

How to cite this paper: Yu, L. (2020). The Exploration of Creative Paths of Cultivating Medical Humanistic Quality under Media Convergence. Open Journal of Social Sciences, $8,417-426$.

https://doi.org/10.4236/jss.2020.83036

Received: December 5, 2019

Accepted: March 24, 2020

Published: March 27, 2020

Copyright $\odot 2020$ by author(s) and Scientific Research Publishing Inc. This work is licensed under the Creative Commons Attribution International License (CC BY 4.0).

http://creativecommons.org/licenses/by/4.0/

\section{(c) (i) Open Access}

\begin{abstract}
With people's increasing emphasis on health and the rapid integration and development of the media, the society has higher requirements for the medical service. As a result, the concepts, goals and modes of talent cultivation in medical colleges and universities have changed. The purpose of this paper is to find out how medical colleges and universities can supplement medical humanities knowledge of medical students, improve medical humanistic ability of medical students and practice the medical humanistic spirit of medical students with the help of media convergence technology and platforms. This paper analyzes the connotation and challenges of contemporary medical humanistic quality by using study methods such as content analysis, field researches, telephone interviews and puts forward the creative paths of cultivating medical humanistic quality from the perspective of media convergence.
\end{abstract}

\section{Keywords}

Media Convergence, Medical Humanistic Quality, Creative Paths

\section{Introduction}

Nowadays, with the improving public requirements for individual health and health care services, the requirements for service attitude, communication ability and other humanistic care of doctors are also increasing. And with the rapid integration and development of the media, the concept, goal and mode of talent cultivation in medical colleges and universities are correspondingly changing. Among all these changing factors, the cultivation of doctors' humanistic quality is becoming more and more important in the cultivation of excellent medical 
talent. Therefore, it is of great academic value in medical education and practical significance in improving the relationship between doctors and patients to explore how to cultivate medical humanistic quality from the aspects of concept, teachers, curriculum and environment in the context of media convergence.

\section{The Contemporary Medical Humanistic Quality in the Context of Media Convergence Era}

"Medical humanistic quality" is the quality closely related to medicine, which is possessed and displayed by doctors in the process of treatment, such as diagnosis and treatment attitude, communication modes, empathy and other ethics care. Scholars divide medical humanistic quality into three categories: medical humanistic knowledge, medical humanistic ability and medical humanistic spirit (Mei, 2016).

In the context of media convergence era, the contemporary medical humanistic quality is renewed with new meanings and characteristics with the intervention of advanced media technology. The first is the interdisciplinary of disciplines. From the perspective of media convergence, the contemporary medical humanistic quality explains the close relationship between medicine and human beings from the perspective of philosophy, communication, art and other basic disciplines, which becomes the relationship between medicine and human sciences. The medical humanistic quality shows the intersection and integration of disciplines and aims to provide more detailed treatment services and humanistic care for patients with the help of the media convergence. The second is the multiform of humanistic care. The media convergence technology has laid a good channel for the embodiment and practice of medical humanities to improve the service, to enhance and shape the personality, ideal realm and value of doctors in various forms and to highlight the characteristics of humanistic care of doctors. The third is the silence of the cultivation way. From the perspective of media convergence, the relationship between the cultivation of humanistic quality and the medical students is more subtle and meticulous. With the help of the media convergence platforms or channels, it is not the billboard influence, but the silent encouragement and guidance.

\section{The Realistic Challenge of Cultivating Medical Humanistic Quality under Media Convergence}

According to site visits, interviews and other research, it is found that although the cultivation of medical humanistic quality has been gradually valued, there are still many challenges in the cultivation of medical humanistic quality because of the media convergence technology development, the change of doctor-patient relationship, multiple values and many other factors.

\subsection{The Emphasis on Medical Humanistic Quality Cultivation Needs to Be Improved}

The cultivation of medical humanistic quality has been highly valued at the na- 
tional level. According to the national strategy of "healthy China 2030", medical workers should not only master advanced medical science and technology, but also have high humanistic quality (Liu, Yang, and Xue, 2018), which makes clear the most basic humanistic quality that contemporary medical students should have. But on the whole, the current medical humanities education is not balanced and the level of humanities knowledge is relatively unsatisfactory.

At the level of school, medical colleges and universities need to pay more attention to the cultivation of medical humanistic quality. Many schools still focus on improving the medical knowledge and skills of college students in terms of educational philosophy and put the promotion of specialized ethics and humanistic quality in a secondary or even marginal position, which will inevitably affect the extent of awareness and attention of teachers and students on improving medical humanistic quality.

At the level of medical students, they themselves still relatively neglect the cultivation of humanistic quality. The interview found that most medical students did not internalize the medical humanistic spirit actively but thought the specialized courses were more important. They thought learning specialized courses well and seeing patients were enough, but they did not really realize the importance of cultivating their own noble medical ethics through humanistic quality cultivation.

\subsection{The Systematization of Medical Humanistic Quality Course System Needs to Be Enhanced}

In terms of curriculum setting, the existing humanities courses in medical colleges are independent and single, and medical students can only obtain humanities knowledge through limited general courses. However, these courses are lack of connection with medical courses, which is bad for the stimulation and cultivation of students' interest in learning and the teaching effect is unreasonable.

In terms of class hours, the heavy specialized courses in medical colleges lead to the shortage of humanities courses. The proportion of medical humanities courses is relatively low and most of them are elective courses without a perfect and reasonable system.

In terms of practical education, the use is not quite appropriate. Clinical practice is the ultimate platform to complete the transformation of medical humanistic education (Zhang, Bai, and Wang, 2014). Without clinical practice, humanistic quality education is bound to be hollow and dull. At present, the content of relevant courses emphasizes theory but neglects time efficiency and it does not combine the cultivation of humanistic quality with medical practice.

In addition, the evaluation standards of medical humanistic quality need to be unified. At present, the relevant evaluation has not incorporated the humanistic quality education into the overall planning of talent cultivation and has not established the evaluation standards of talent quality to coordinate the development of knowledge, ability and quality. The performance of students' participation in various cultural activities and humanistic practices has not been included 
in the evaluation standards (Ye, 2010). So the contents and means of evaluation need to be further improved and unified.

\subsection{The Teaching Staff of Medical Humanistic Quality Needs to Be Refined}

The level of teachers' humanistic quality has a direct impact on the results of humanistic education in medical colleges and universities. Most of the humanities education participants in medical colleges and universities in China are clinicians, who have comprehensive clinical knowledge and technology but are relatively weak in humanistic quality teaching (Ren, Xiong, and Shi, 2015).

Firstly, the clinical teachers do not have a good understanding of the humanistic care spirit cultivation of medical college students. And they often focus on propagating the doctrine but ignore imparting specialized knowledge and resolving doubts. Secondly, in the later stage of clinical teaching, most teachers have the tasks of both the front-line diagnosis and treatment work and the scientific research and clinical teaching. In the clinical teaching process, in addition to teaching students clinical specialized knowledge such as patient inquiry, drug use, and standardized operation, it is difficult for teachers to systematically develop students' medical ethics, communication skills between doctors and patients, and humanistic care spirit. So the medical humanistic knowledge learned by students at school can not be continued and the courses have faults, which lags behind the cultivation of students' humanistic quality progress. Finally, the humanistic cultivation team of medical college is mainly composed of Marxist college teachers and college counselors. Due to the lack of medical knowledge, the theory of medical humanities cannot be well integrated with medical practice and cannot resonate with students.

\subsection{The Current Situation of the Development of Media Convergence in Medical Colleges Is Not Optimistic}

The media convergence platforms have become an important carrier of medical humanities knowledge and spirit dissemination. Most medical colleges and universities have campus websites, WeChat official accounts and other mass media and gradually begin media integration. But at present, the related media integration is mostly at the stage of combining traditional media with new media, that is, the content is simply transplanted from traditional media to new media platforms for display. In terms of concept, most colleges and universities do not have a deep understanding of the media convergence as a new communication channel and new media with rich display forms and interactive modes. They are lack of cognition on the information receiving habits of college students and lack of research and exploration on the interior building of media convergence. In terms of technical equipment, most of the relevant media hardware is relatively old, which is not suitable for the high-speed development of information in campus life and does not give full play to the unique role of short video in the pattern of media convergence. In terms of media team, in most colleges and 
universities, some full-time staff lead the student teams to be responsible for the campus media operation. They are short of journalists with new network thinking and their content and form are limited by human resources, so they can not provide relatively high-quality humanistic information in line with today's reading habits of teachers and students (Li, 2019).

\section{Creative Paths of Cultivating Medical Humanistic Quality under Media Convergence}

From the perspective of the media convergence, on the one hand, the media convergence brings many challenges to the cultivation of medical humanistic quality. On the other hand, the media convergence can be used as a mean, channel and platform to carry out targeted creative path exploration to solve the practical challenges to the cultivation of medical humanistic quality mentioned before. This paper puts forward the creative paths of collaboratively cultivating medical humanistic quality, which are renewing the cultivation concept of humanistic quality, improving the teaching staff of humanistic cultivation, establishing curriculum systems with creative characteristic, optimizing the public opinion environment of media convergence and building online and offline humanistic practice bases. In conclusion, medical colleges and universities should strive to closely integrate the media convergence technology and platforms, supplement medical humanities knowledge of medical students, improve medical humanistic ability of medical students and practice the medical humanistic spirit of medical students.

\subsection{Renewing the Cultivation Concept of Humanistic Quality}

First of all, we should establish the concept of bringing the cultivation of medical humanistic quality into the top-level design. We should establish and integrate new medical viewpoint in the era of new media convergence. We should change the traditional ideas and dialectically treat the influence of media technology on the information dissemination way and content. We should understand the new laws of network communication, such as digital developing, user experience, interaction and short video advantage, and realize the medical humanities innovation cultivation by combining the information communication mode of media convergence. Education can be carried out through MicroBlog, WeChat, school website and other platforms.

Next, to change teachers' concept of humanistic education, we should increase the use of media convergence as a new mean and also add more context of media literacy in the course of theoretical lecturing. It is necessary to enhance the ability of medical students to use the media convergence platforms and study and judge the media information, so as to deepen their understanding of the practice of medical humanistic spirit in reality and then internalize the medical humanistic theory and the health humanistic quality into their own comprehensive quality and then apply the quality consciously in the action of building a healthy society and a healthy China (Tan \& Xu, 2018). 


\subsection{Improving the Teaching Staff of Humanistic Cultivation}

Firstly, we should improve the medical knowledge learning of humanities teachers and their knowledge structure. The teachers of humanities courses need not only humanistic spirit, but also medical specialized knowledge, which can be integrated into daily teaching. So they can change the original knowledge structure and specialized attitude of students and improve their specialized ethics quality such as humanistic consciousness and spirit.

Secondly, we should guide specialized teachers to attach importance to humanistic education and integrate humanities into teaching. Only when the specialized teachers themselves have good medical humanistic quality can they truly understand the relationship between medical science and medical humanities and can they consciously and purposefully integrate medical humanistic education into the teaching of specialized courses. They not only teach students medical knowledge, but also teach students the view of life, values, learning attitude and professionalism, so that students can fully understand the humanistic thoughts contained in medicine.

In addition, we should boost the application of teachers' media convergence skills and improve their media literacy. We should innovate teacher training methods, guide teachers to take the initiative to integrate the media and teaching and improve teachers' practical application ability of media convergence information technology through various training and practice. We should study the motivate mechanism so that we can encourage teachers to use media convergence technology more, combine it with the classroom teaching and gradually adapt to and be familiar with the intelligent tutoring of media convergence (Ping and $\mathrm{Du}, 2016)$. At the same time, we should improve the media literacy of medical humanities teachers. The teachers should learn to use the right way to identify media information and guide medical students not to be affected by negative information in complex information so as to strengthen their beliefs and ideals to study medicine.

\subsection{Establishing Curriculum Systems with Creative Characteristic}

We should enrich the humanities courses, establish a systematic medical humanities course system and abandon the single method of lecturing. With the media convergence, we can let students focus on the courses through different teaching forms and participation forms and experience the charm of humanities and the relationship between humanities and medicine, which can improve their humanistic feelings in the process of acceptance.

In terms of curriculum system, the curriculum system should cover basic medical humanities knowledge, medical professional ethics, mental health education and other courses (Liu and Wang, 2018). The general medical humanities courses can help students understand medical knowledge under the macro background of strong humanities, deeply understand patients and diseases, and then establish a sense of social responsibility. The specialized medical humani- 
ties course can help students understand the occurrence and development of diseases more deeply and improve their ability to deal with clinical ethical, social and legal issues.

In terms of curriculum form, it is necessary to set up a multidimensional system of compulsory courses, elective courses, extracurricular practice and online cross-campus course selection, and innovate the teaching form of medical humanities education. We can explore the integration of medicine and humanity, interpret the social problems of medical development from the perspective of philosophy, art, law, psychology and other disciplines, and correctly understand the reality of doctor-patient relationship and medical reform. The relevant courses can be opened to the whole country and even the world through the media convergence platforms.

In terms of curriculum content, it should keep pace with the time. So we should compile and publish new series of textbooks for core courses of medical humanities, which includes medical introduction, medical philosophy, medical law, medical sociology, doctor-patient communication, etc. (Medicine and Philosophy, 2015). The content of textbooks should cover the branches of humanities, such as arts, education, philosophy, archaeology, psychology, ethics, human rights, law, politics and military.

\subsection{Optimizing the Public Opinion Environment of Media Convergence}

The public opinion environment and cultural atmosphere of medical colleges should strongly reflect the cultural characteristics of humanistic care, benevolence and harmony, and cultivate the medical humanistic quality of students in a subtle way. Under the background of media convergence, the time and space of medical humanistic quality education are flexible and the humanity education is not limited to a specific time and environment (Liu, 2019). With the help of media convergence technology, medical colleges and universities can carry out all-round and multi-perspective humanistic quality education for medical students. The education should go deep into students'study, life and work and cultivate their humanistic quality in a silent way.

Firstly, we should attach importance to the development of campus media and enhance its affinity. The campus media development will be raised to the height of schools' outward image and internal cohesion. We should take short video as the breakthrough of media convergence development to enhance the vividness and depth of information dissemination. And then we can enhance the cohesion between the campus new media and medical students, improve the affinity between media and students, attract more teachers and students to pay attention to campus media, and expand its scope of communication and enhance its communication capabilities.

Secondly, we should tell the campus stories well and form a unique brand. With the rise of short video platforms, its content is close to the real life of medical students, which is easy to resonate with the public. The content of short 
videos should be about the campus life rules and layers that teachers and students pay attention to. We can use the micro perspective to cut into the story main line and use easily understood language of sound and picture to tell the details of ordinary characters on campus. We can set up a separate column of short videos that regularly launches short video products and continuously push short videos with ideas, temperature and quality. So we can form a unique brand with characteristics and innovation and stick to the audience of medical students.

Thirdly, we should establish special report platforms and publicize typical models. Through the establishment of special websites and WeChat official accounts, we can create a new and lively atmosphere for media convergence education, strengthen the dissemination of humanities knowledge, stories of humanity, and medical celebrities. We can develop online humanistic activities with rich connotation, convey humanistic care between doctors and patients, and promote the spirit of medical humanism.

Fourthly, we should carry out public opinion guidance and create a civilized cyberspace. The network is the main environmental variable that affects the cultivation of medical humanities and it directly affects the world views, values and philosophy of medical students. Therefore, it is necessary to build a network public opinion assessment and guidance system, which can actively and effectively manage network public opinion, create a civilized cyberspace and guide medical students to accept correct values and spread positive energy.

\subsection{Building Online and Offline Humanistic Practice Bases}

The cultivation of medical humanistic quality not only depends on classroom education and environmental influence, but also relies on the practical activities to internalize and enhance medical humanistic education. We can integrate social resources to build humanistic practice bases and online and offline volunteer service platforms by means of college-college cooperation, government-college cooperation, hospital-college cooperation, research-college cooperation, etc. So we can cultivate students' sense of social responsibility and humanity spirit of benevolence and love.

In the process of providing voluntary services for patients, medical students will receive humanistic care education in person and solve the problems of how to care for patients and how to be trusted by themselves. The relevant experiences will strengthen their understanding of patients' physical and mental pain, enhance their understanding of patients' psychological needs and promote medical students' deep understanding of humanistic care and practical practice of humanistic spirit. In addition, volunteer services can provide medical students with effective ways to improve and broad platforms to exercise in order to solve the problem that some medical students are lack of communication skills, initiative and self-confidence.

In the cooperation cultivation of college-college cooperation, government-college cooperation and hospital-college cooperation, medical colleges and universities, 
together with their cooperative scientific research institutions, government units and affiliated hospitals, can build humanistic medicine practice bases and patriotism education bases so that we can hold activities such as open day of scientific research and medical experts' volunteer clinic. Through these various practical activities, medical students can gain personal experiences and feelings of medical humanistic care, which can stimulate their patriotic enthusiasm and sense of historical mission and then firm their ideals and beliefs to study medicine.

\section{Conclusion}

In conclusion, the cultivation of medical humanistic quality is not an immediate effect. It needs a long-term investment with whole directions and whole members. Under the background of high integration and rapid development of media technology, the media convergence technology and platforms can play a unique role in the cultivation of medical humanistic quality. At present, there are many deficiencies in the cultivation of medical humanistic quality, which greatly restricts the cultivation of excellent medical talents. It needs to start with the current situation of medical humanistic quality cultivation and actively explore the creative paths of collaborative cultivation of medical humanistic quality. We should go deep into the innovation in aspects of renewing the cultivation concept of humanistic quality, improving the teaching staff of humanistic cultivation, establishing curriculum systems with creative characteristics, optimizing the public opinion environment of media convergence and building online and offline humanistic practice bases.

\section{Conflicts of Interest}

The author declares no conflicts of interest regarding the publication of this paper.

\section{References}

Li, Y. G. (2019). The Function of Short Video in the Mode of University Media Convergence Communication. New Media Research, 5, 83-84+121.

Liu, X. F., \& Wang, X. H. (2018). Connotation and Practice of Humanistic Quality Education for Medical Students. Data of Culture and Education, No. 17, 153-154.

Liu, Y. (2019). Innovation of College Ideological and Political Education from the Perspective of Media Convergence. Learning Weekly, 391, 21.

Liu, Y., Yang, X. X., \& Xue, T. (2018). Cultivation of Medical Student's Humanistic Quality from the Perspective of "Healthy China 2030". Industrial \& Science Tribune, 17, $115-116$

Medicine and Philosophy (2015). Education Reform Outline of Humanistic Medicine Education. Medicine and Philosophy, 36, 1-7+10.

Mei, L. (2016). The Research and Empirical Study on the Evaluating Methodology for Medical Humanistic Quality in the National Medical Certification Examination. Chongqing: Third Military Medical University. 
Ping, H. G., \& Du, Y. L. (2016). "Internet + Education": Opportunity, Challenge and Countermeasure. Modern Education Management, 310, 19-24.

Ren, J. B., Xiong, X. R., \& Shi, T. J. (2015). Problems and Countermeasures in Medical Humanities Education. Health Vocational Education, No. 6, 7-8.

Tan, D. H., \& Xu, Y. M. (2018). Practice Path Optimization of Medical Students' Humanistic Education under the Background of Healthy China Strategy. Chinese Medical Ethics, 31, 1217-1220.

Ye, W. A. (2010). Thought and Exploration of Humanistic Education for Medical Students. China Higher Medical Education, No. 6, 32-33.

Zhang, J. Y., Bai, Y. L., \& Wang, H. (2014). Clinical Practice Is the Ultimate Platform of Medical Humanistic Education. Medicine and Philosophy, 35, 75-77. 